\title{
TANGGAPAN PENONTON DI DAERAH KETAPANG KABUPATEN KOTAWARINGIN TIMUR KALIMANTAN TENGAH TERHADAP ACARA DOKUMENTER DUA DUNIA TRANS 7
}

\section{Hamdani}

UIN Antasari Banjarmasin

\begin{abstract}
This research comes from an event titled Two World which is a show owned by Trans7. This event has a lot of religious messages through jinmelalui advice through the body of the mediator (genie penetrates into the human body). The purpose of this study is to know the level of material understanding of the World Two Trans 7 event based on existing categories of audience in Ketapang Kotawaringin East of Central Kalimantan against this Two World event. This research method is descriptive qualitative field research (field) in town in Middle Kalimantan region named Sampit and more specifically Ketapang Village area So with the data obtained, the authors conducted a questionnaire that has contained questions about the response to the World Two event in Trans7.In addition, also coupled with various manuals in theory to do this research. The results of this study can be seen that there are messages of da'wah in this event though many smells of mystic things. As for the religious message about belief (akidah), Worship (shariah) and Moral (akhlak). Also in the event Two World also, from the results of the question with the jinn is implied ban on begging to the deceased. Moreover, if to adore them. Remember that the dead only require prayer posts, not for worship. Those are some of the sage messages implied by the jinns' rantings in the Worlds Two show that aired on Trans7. Seeing some of the precious messages that have been conveyed by the Jinn, men should be ashamed for being nasehati by the people of the unseen world that is identical with the evil and sinister impression.
\end{abstract}

Keywords: two worlds, audience, dakwah

\section{Pendahuluan}

Dalam agama Islam, umat Islam sudah tahu akan adanya dunia gaib. Sebagai manusia awam sering percaya setalah mendapatkan penjelasan dari keyakinan yang diyakini.Percaya atau tidak dunia ini memang ada namun kasat mata bagi oranng
awam.Bagi manusia, kekuatan gaib tersebut kadang diluar akal.Oleh sebab itu, terkadang tidak sedikit dari manusia yang tidak mempercayai hal itu.Ada juga yang takjub dengan kekuatan tersebut dan kemudian mengagung-agungkannya.

Sebagai umat muslim, wajib percaya dengan adanya dunia gaib. Namun, harus kita barengi dengan iman kepada Allah Sang 
Maha Kuasa. Tidak sedikit dari bangsa manusia menjadi "Syirik" setelah mengetahui kekuatan dunia gaib yang terkadang diluar logika.Banyak manusia yang menyimpang dari Allah dikarenakan kekuatan ini.Baik karena harta, kekuatan, dll.

Dalam hal syirik ini Allah berfirman dalam surah An-Nisa ayat 48 :

"Sesungguhnya Allah tidak akan mengampuni dosa syirik, dan Dia mengampuni segala dosa yang selain dari (syirik) itu, bagi siapa yang dikehendakiNya. Barangsiapa yang mempersekutukan Allah, Maka sungguh ia telah berbuat dosa yang besar. '(QS. An-Nisa' : 48)

Syirik adalah menjadikan sekutu bagi Allah.Seperti berdo'a kepada Allah, tetapi juga berdo'a kepada selain Allah atau melakukan ibadah yang dilakukan untuk selain Allah, seperti menyembelih, takut, harap dan cinta.Syirik adalah dosa besar, dan Allah sangat murka pada orang yang syirik.Selain itu, Allah mengharamkan surga bagi orang yang musyrik dan dia kekal didalam neraka jahannam. Segala amalan baiknya pun tidak akan diterima dan tidak akan mendapatkan syafa'at untuknya. Karena musyrik adalah orang yang paling bodoh diantara orang yang bodoh tentang

Albiwar Jurnal Ilmu dan Teknik Dakwah Vol. 05 No. 09 Januari - Juni 2017
Allah.Yang mana dia menjadikan sekutu bagi Allah dan hal itu merupakan kedzaliman yang sangat parah.

Acara dokumenter "Dua Dunia" adalah salah satu acara di Trans7, yang mana dari acara ini sering mengungkap dan meluruskan mitos-mitos yang ada di masyarakat yang di anggap dapat membuat masyarakat setempat dan lain menjadi syirik. Dari acara ini sering mengungkap hal gaib, mereka menggunakan informasi dari jin yang mana informasinya terkadang bisa benar maupun bohong. Dalam acara tersebut sang ustadz Hakim Bawazier sebelumnya sering memberitahukan kepada penonton bahwa informasi dari jin tidak dapat dipercaya semua. Karena kebanyakan dari bangsa mereka adalah pembohong.Dalam acara ini banyak memiliki hikmah Islami yang dapat diambil.Membuat penonton makin mengetahui bahwa hanya kekuatan Allah lah yang paling kuasa.

Perlu diingatkan, manusia maupun jin wajib hanya menyembah kepada Allah SWT. Karena Dia lah Sang Khalik dunia ini.Dalam firman-Nya yang berbunyi.

"dan aku tidak menciptakan jin dan manusia melainkan supaya mereka mengabdi (beribadah) kepada-Ku." (QS. Adz-Dzariyaat : 56). 
Dari ayat tersebut menjelaskan bahwa manusia hanya dibolehkan menyembah Allah. Karena jin yang membuat manusia syirik juga wajib menyembah Allah. Jadi sepatutnya kita hanya menyembah Allah SWT.Bukan menduakan Allah dengan makhluk lain (meminta pertolongan Dunia Gaib).

Tujuan Penelitian ini adalah untuk efek dari acara sdua dunia dalam membentuk akidah tauhid masyarakat di daerah kelurahan Ketapang Kabupaten Kotawaringin Timur (Kalteng); Materi pesan dakwah yang di sampaikan dan metode yang di gunakan dalam penyampaiannya; Hasil yang di capai dari penyiaran acara dua dunia tersebut untuk penonton di daerah Ketapang Kabupaten Kotawaringin Timur (Kalteng).

\section{Pembahasan}

\section{Teori Komunikasi}

Dalam teori komunikasi ada teori yang terkenal yaitu model komunikasi dari Harold Lasswell yang dianggap oleh para pakar komunikasi yang paling awal dalam perkembangan teori komunikasi (1948). Lasswell menyatakan bahwa cara yang terbaik untuk menerangkan proses komunikasi adalah menjawab pertanyaan : Siapa? (Who), Berkata apa? (Says What), Melalui apa? (In Which Channel), Kepada siapa? (To Whom), Dengan efek apa? (With What Effect).

1. Who? (siapa/sumber).

Sumber/komunikator adalah pelaku utama/pihak yang mempunyai kebutuhan untuk berkomunikasi atau yang memulai suatu komunikasi, bisa seorang individu, kelompok, organisasi, maupun suatu Negara sebagai komunikator.

2. Says What? (pesan).

Apa yang akan disampaikan atau dikomunikasikan kepada penerima (komunikan), dari sumber (komunikator) atau isi informasi. Merupakan seperangkat symbol verbal/non-verbal yang mewakili perasaan, nilai, gagasan/maksud sumber tadi.Ada 3 komponen pesan yaitu makna, symbol untuk menyampaikan makna, dan bentuk/organisasi pesan.

3. In Which Channel? (saluran/media).

Wahana/alat untuk menyampaikan pesan dari komunikator (sumber) kepada komunikan (penerima) baik secara langsung (tatap muka), maupun tidak langsung (melalui media cetak/elektronik dll). 
4. To Whom? (untuk siapa/penerima).

Orang, kelompok, organisasi, suatu Negara yang menerima pesan dari sumber.Disebut tujuan (destination), pendengar (listener), khalayak (audience).Komunikan, penafsir atau penyandi balik (decoder).

\section{With What Effect? (dampak/efek)}

Dampak atau efek yang terjadi pada komunikan (penerima) setelah menerima pesan dari sumber, seperti perubahan sikap, bertambahnya pengetahuan, dll.

Dari kelima unsur tersebut contoh komunikasi guru dengan muridnya. Guru sebagai komunikator harus memiliki pesan yang jelas yang akan disampaikan kepada murid atau komunikan. Setelah itu guru juga harus menentukan saluran untuk berkomunikasi baik secara langsung atau tidak langsung.Setelah itu guru harus menyesuaikan topic/diri/tema yang sesuai dengan umur si komunikan, juga harus menentukan tujuan komunikasi/maksud dari pesan agar terjadi dampak/effect pada diri komunikan sesuai dengan yang diinginkan.

\section{Teori tentang Tanggapan}

Tanggapan adalah proses yang rumit bagi yang ramai memilih, mengelola dan menafsirkan stimulasi pancaindra untuk mendapatkan gambaran yang lebih jelas dan bermakna.(Serverin Werner J 1988).

Clark Hull juga menggunakan variabel hubungan antara stimulus dan respon untuk menjelaskan pengertian belajar.Namun dia terpengaruh oleh teori evolusi Charles Darwin. Bagi Hull, seperti halnya teori evolusi, semua fungsi tingkah laku bermanfaat terutama untuk menjaga agar organisme tetap bertahan hidup. Oleh sebab itu Hull mengatakan kebutuhan biologis (drive) dan pemuasan kebutuhan biologis (drive reduction) adalah penting dan menempati posisi sentral dalam seluruh kegiatan manusia, sehingga stimulus (stimulus dorongan) dalam belajar pun hamper selalu dikaitkan dengan kebutuhan biologis, walaupun respon yang akan muncul mungkin dapat berwujud macammacam.

Program-program pembelajaran seperti Teaching Machine, Pembelajaran berprogram, modul dan program-program pembelajaran lain yang berpijak pada konsep hubungan stimulus-respons serta mementingkan factor-faktor penguat Albiwar Jurnal Ilmu dan Teknik Dakwah Vol. 05 No. 09 Januari - Juni 2017 
(reinforccement), merupakan program pembelajaran yang menerapkan teori belajar yang dikemukakan Skiner. Skinner dan tokoh-tokoh lain pendukung teori behavioristik memang tidak menganjurkan digunakannya hukuman dalam kegiatan pembelajaran. Namun apa yang mereka sebut dengan penguat negative (negative reinforcement) cenderung membatasi pebelajar untuk berpikir dan berimajinasi.

Menurut Guthrie hukuman memegang peranan penting dalam proses belajar. Namun ada beberapa alasan mengapa Skinner tidak sependapat dengan Guthrie, yaitu :

- Pengaruh hukuman terhadap perubahan tingkah laku sangat bersifat sementara;

- Dampak psikologis yang buruk mungkin akan terkondisi (menjadi bagian dari jiwa si terhukum) bila hukuman berlangsung lama;

- Hukuman yang mendorong si terhukum untuk mencari cara lain (meskipun salah dan buruk) agar ia terbebas dari hukuman. Dengan kata lain, hukuman dapat mendorong si terhukum melakukan hal-hal lain yang kadangkala lebih buruk daripada kesalahan yang diperbuatnya.
Skinner lebih percaya kepada apa yang disebut sebagai penguat negatif. Penguat negative tidak samadengan hukuman. Ketidaksamaannya terletak pada bila hukuman harus diberikan (sebagai stimulus) agar respon yang muncul berbeda dengan yang sudah ada, sedangkan penguat negatif (sebagai stimulus) harus dikurangi agar respon yang sama menjadi semakin kuat. Misalnya, seorang pembelajar perlu dihukum karena melakukan kesalahan.Jika pembelajar tersebut masih saja melakukan kesalahan, maka hukuman harus ditambah. Tetapi jika sesuatu tidak mengenakan pembelajar (sehingga ia melakukan kesalahan) dikurangi (bukan malah ditambah) dan pengurangan ini mendorong pembelajar untuk memperbaiki kesalahannya, mak inilah yang disebut penguat negative. Lawan dari penguat negative adalah penguat positif (positive reinforcement).Keduanya bertujuan untuk memperkuat respon.Namun bedanya adalah penguat positif menambah, sedangkan penguat negative adalah mengurangi agar memperkuat respons. 


\section{Iman Kepada Hal Gaib}

Kriteria orang yang bertakwa pertama Allah disebutkan disebutkan dalam firman-Nya ialah meyakini hal-hal ghaib. Allah berfirman :

"Alif laam miin. Kitab (Al Quran) ini tidak ada keraguan padanya; petunjuk bagi mereka yang bertaqwa,(yaitu) mereka yang beriman kepada yang ghaib, yang mendirikan shalat, dan menafkahkan sebahagian rezki yang Kami anugerahkan kepada mereka." (QS. Al-Baqarah : 1-3)

Abdullah bin Mas'ud menjelaskan, "pengertian ghaib ialah sesuatu yang tidak bisa diindra. Allah Rasul-Nya telah memberitahukan perkara (ghaib) ini kepada kita."(Yasir Amri \& Syahirul Alim Al-Adib LC. 2012).

Berdasarkan ayat dan keterangan tersebut, orang beriman wajib meyakini halhal ghaib.Yaitu beriman kepada Allah. Malaikat, dan hari akhir, termasuk meyakini adanya jin dialam ini. Keyakinan pada halhal ghaib ini juga merupakan pokok dalam aqidah Islam.

Secara spesifik, keimanan pada hal ghaib yang ingin ditegaskan adalah beriman pada keberadaan jin. Keberadaan jin itu hakikat, bukan khurafat. Bangsa jin sudah tida asung lagi bagi kita. Sekalipun wujudnya tidak kasat mata atau makhluk ghaib, dampak perbuatannya sering bisa dirasakan dan dilihat secara nyata oleh manusia.Sebagai orang beriman, kita wajib mempercayai keberaddaan dan campur tangannya dialam manusia.Al-Qur'an dan As-Sunnah banyak menyebutkan hal ini.

Untuk lebih jelasnya, inilah ayat-ayat yang menyebutkan eksistensi Jin dialam manusia, berbeda dengan manusia dan malaikat, Allah menciptakan jin dari api. Allah SWT berfirman:

"dan Sesungguhnya Kami telah menciptakan manusia (Adam) dari tanah liat kering (yang berasal) dari lumpur hitam yang diberi bentuk.27. dan Kami telah menciptakan jin sebelum (Adam) dari api yang sangat panas." (QS. Al-Hijr: 26-27)

Seperti makhluk-makhluk lainnya. Jin juga memerlukan makanan dan tempat tinggal. Makanan jin adalah tulang yang disebut nama Allah (ketika menyembelihnya) dan kotoran hewan. Nabi bersabda :

\footnotetext{
"Bagi kalian setiap tulang yang disebut nama Allah (ketika menyembelihnya) yang jatuh ke tangan kalian, yang paling banyak dagingnya, dan juga setiap kotoran hewan."

Menegaskan hadits diatas, Nabi melarang istinja' dengan kotoran kering. Beliau bersabda, 'Jangan beristinja' dengan keduanya, karena keduanya adalah makanan
} 
saudara kalian (bangsa jin).” Jin mengambil sebuah tempat untuk ditinggali.Umumnya mereka tinggal ditempattampat kotor dan tidak berpenghuni.Tapi kadang ada juga tinggal dirumah yang ditempati manusia.

Syaikh Taqiyuddin bin Taimiyah berkata, "Tidak satu pun dari kelompok kaum muslimin yang mengingkari keberadaan jin, demikian juga kaum kafir secara keseluruhan. Karena keberadaan jin disebutkan berita para Nabi secara mutawatir dan mesti diketahui oleh masyarakat secara khusus dan umum. yang mengingkari keberadaan jin hanyalah sekelompok kecil para filusuf dungu dan orang-orang yang seperti mereka. (Al-Imam Jalaludin As-Suyuthi. 2011).

\section{Al-Qadhi Abu Bakar Al-Baqillani} berkata, "sebagian besar penganut Qadariyah menetapkan Keberadaan jin pada zaman dahulu, namun mereka Menafikan keberadaan jin pada zaman sekarang. Ada diantara mereka yang tetap meyakini keberadaan jin yang tidak dapat dilihat karena halusnya tubuh mereka dan dapat ditembus cahaya. Diantara mereka ada yang berkata, "jin dapat dilihat karena mereka tidak berwarna."

Meminta bantuan dari orang lain secara serius, demi suatu kebutuhan, hanya dapat terjadi jika yang memerlukannya meyakini kekuatan dan kemampuan orang yang dimintainya bantuan untuk memenuhinya. Kemampuan ini adakalanya bersifat lahiriah dan materil, seperti misalnya apabila kita meminta dari seseorang kepada kita air minum.Akan tetapi, adakalanya kekuatan tersebut bersifat ghaib, diluar kebiasaan umum atau berlawanan dengan hokum alamiah.

Misalnya jika seseorang percaya sepenuhnya bahwa Imam Ali a.s pernah mencabut pintu benteng Khaibar dengan suatu kekuatan ghaib, memberi kesembuhan bagi orang yang menderita penyakit yang biasanya tak dapat disembuhkan tanpa obat dan operasi.(Syaikh Ja'far Subhani, Tauhid dan Syirik. Hal 118).

\section{Letak Geografis Dan Luas Wilayah}

Kelurahan ketapang adalah kelurahan yang wilayahnya terletak di perbatasan antara erkotaan dan pedesaan di Kecamatan Mentawa Baru Ketapang yang juga terletak di Ibukota Kabupaten Kota Waringin Timur.Dengan luas wilayah berdasarkan data dari BPS. $10.000 \mathrm{Ha}$ setelah pada bulan Desember 2009 diadakan penataan batas antara Kelurahan dan Desa di wilayah Kecamatan Mentawa Baru Ketapang maka luas wilayah Kelurahan Albiwar Jurnal Ilmu dan Teknik, Dakwah Vol. 05 No. 09 Januari - Juni 2017 
Ketapang seluas Ha namun dengan berkurangnya luas wilayah tersebut tidak mengurangi jumlah penduduk karena daerah yang terptong adalah tidak ada penduduknya (Tanah kosong/ semak belukar)

\section{Jumlah Penduduk}

Kelurahan Ketapang terdiri dari 51 RT dan 8 RW dengan luas wilayah 10.000 Ha. Jumlah penduduk berdasarkna data dari Dinas Kependudukan dan Catatan sipil sampai dengan 31 Mei 2011 adalah berjumlah kurang lebih 25.717 jiwa terdiri dari 15.111 laki-laki dan 10.606 perempuan dengan jumlah Kepala Keluarga 5.053 Kepala Keluarga.

\section{Keadaan Penganut Agama}

Tabel 1. JUMLAH MASYARAKAT KELURAHAN KETAPANG BERDASARKAN KATEGORI AGAMA

\begin{tabular}{|c|c|c|c|c|c|c|c|}
\hline $\begin{array}{l}\mathrm{N} \\
\mathrm{O}\end{array}$ & $\begin{array}{c}\text { Jeni } \\
\text { s } \\
\text { Kel } \\
\text { ami } \\
\text { n }\end{array}$ & $\begin{array}{c}\text { Isla } \\
\text { m }\end{array}$ & $\begin{array}{c}\text { Kris } \\
\text { ten }\end{array}$ & $\begin{array}{l}\text { Kat } \\
\text { olik }\end{array}$ & $\begin{array}{c}\mathrm{Hi} \\
\mathrm{nd} \\
\mathrm{u}\end{array}$ & $\begin{array}{c}\mathrm{Bu} \\
\mathrm{dh} \\
\mathrm{a}\end{array}$ & $\begin{array}{l}\text { Kong } \\
\text { huchu }\end{array}$ \\
\hline 1 & $\begin{array}{c}\text { Lak } \\
\text { i- } \\
\text { laki }\end{array}$ & $\begin{array}{l}11 . \\
040\end{array}$ & $\begin{array}{l}1.0 \\
33\end{array}$ & 402 & $\begin{array}{c}20 \\
9\end{array}$ & $\begin{array}{c}32 \\
3\end{array}$ & 9 \\
\hline 2 & $\begin{array}{l}\text { Per } \\
\text { emp } \\
\text { uan }\end{array}$ & $\begin{array}{c}10 . \\
376\end{array}$ & $\begin{array}{l}1.2 \\
46\end{array}$ & 400 & $\begin{array}{c}21 \\
0\end{array}$ & $\begin{array}{c}31 \\
4\end{array}$ & 7 \\
\hline & $\begin{array}{l}\text { Jum } \\
\text { lah }\end{array}$ & $\begin{array}{l}21 . \\
416\end{array}$ & $\begin{array}{l}2.2 \\
79\end{array}$ & 802 & $\begin{array}{c}41 \\
9\end{array}$ & $\begin{array}{c}33 \\
7\end{array}$ & 16 \\
\hline
\end{tabular}

\section{Tempat Ibadah}

Tabel 2. JUMLAH TEMPAT IBADAH KEAGAMAAN DI KELURAHAN KETAPANG

\begin{tabular}{|c|l|c|}
\hline No & Nama Tempat Ibadah & Jumlah \\
\hline 1 & Masjid & 8 buah \\
\hline 2 & Gereja & 1 buah \\
\hline 3 & Pura & 1 buah \\
\hline 4 & Mushalla & 29 buah \\
\hline
\end{tabular}




\section{Pendidikan}

Tabel 3. JUMLAH SARANA

PENDIDIKAN DI KELURAHAN

KETAPANG

\begin{tabular}{|c|l|c|c|}
\hline No & \multicolumn{1}{|c|}{$\begin{array}{c}\text { Sarana } \\
\text { Pendidikan }\end{array}$} & 2009 & 2010 \\
\hline 1 & SLTA/ Sederajat & 1 & 1 \\
\hline 2 & SLTP/ Sederajat & 2 & 2 \\
\hline 3 & Sd/ Sederajat & 6 & 6 \\
\hline 4 & $\begin{array}{l}\text { Lembaga } \\
\text { Pendidikan } \\
\text { Agama/ Potren }\end{array}$ & 2 & 2 \\
\hline 5 & $\begin{array}{l}\text { Lembaga } \\
\text { Pendidikan lain } \\
\text { (kursus/ } \\
\text { sejenisnya) }\end{array}$ & 1 & 2 \\
\hline
\end{tabular}

\section{Mata Pencaharian}

Masyarakat Kelurahan Ketapang mempunyai berbagai jenis macam mata pencaharian.Namun pada umumnya masyarakatnya menjadi petani dan pedagang.Sedangkan sebagiannya sebagai pegawai, pengusaha, wiraswasta dan lainlain.

\section{Keadaan Sosial Budaya}

Pada umumnya keadaan social penduduk Kelurahan Ketapang adalah kegotongroyongan dan toleransi antar sesame.Adapun unsur-unsur kebudayaan yang melekat serta berpengaruh terhadap masyarakatnya adalah unsure agama Islam. Namun masih ada sedikit masuk unsure budaya dayak setempat, sehingga kegiatan adat setempat bisa bercampur dengan unsure agama Islam, seperti contoh mandi safar.

\section{Data-data Responden}

Adapun dari hasil sampel yang di dapat dari metode yang penulis pakai. Di dapat responden berjumlah 27 orang yang di jabarkan sebagai berikut:

- Kategori Sekolah Umum 9 orang

- Kategori Sekolah Agama 9 orang

- Kategori Tidak Bersekolah Lagi 9 orang

Isi Pesan Dari Acara Dua Dunia Trans7 Pada Masing-Masing Episode

Hasil dari 9 episode acara Dua Dunia Trans7 dapat peneliti simpulkan data berdasarkan dari masing-masing episode. Sebagaimana yang peneliti jabarkan di bawah ini:

a. Pada tanggal 2 Oktober 2013 dengan judul "Rahasia Dusun Kasuruan"

Berawal dari mitos yang ada di daerah dusun kasuran (Sleman, Jogjakarta).Seluruh dari masyaraktnya Albiwar Jurnal Ilmu dan Teknik Dakwah Vol. 05 No. 09 Januari - Juni 2017 
mempercayai bahwa adanya larangan tidur menggunakan kasur kapuk.Setelah mendapatkan beberapa informasi yang ada.Ustadz Hakim Bawazier (praktisi supernatural) menyimpulkan bahwa memang adanya bukti dari sejarah desa tersebut.Bahwa desa kasuran identik dengan kasur.Hikmahnya yang perlu di ambil hendaknya kita hanya memohon pertolongan dan perlindungan hanya kepada Allah dan jangan percaya dengan suatu hal yang membuat kita melupakan Allah.

b. Pada tanggal 4 Oktober 2013 dengan judul "Bekas Galian Pasir Cimarati"

Sebuah kisah di kalangan masyarakat di desa Puntet Astana Jabura Kabupaten Cirebon.Tentang ada sebuah tampat yang merupakan bekas galian pasir cimarati dan tempat tersebut telah menelan banyak korban.Dipercayai bahwa tempat tersebut sering meminta tumbal anak-anak.

Ustadz Ujang menyimpulkan Allah menciptakan bumi dan langit agar manusia bertafakkur.Yaitu menjaga dan melestarikan ciptaan Allah sehingga Allah tidak marah terhadap suatu umat. Selain itu, ustadz menerangkan bahwa jin tidak bisa membunuh manusia. Semua itu terjadi karena takdir Allah.

c. Pada tanggal 9 Oktober 2013 dengan judul "Tabir Gaib Karang Paranje"

Berawal dari pantai berupa bentangan karang di selatan Garut dan sering di sebut Karang Paranje. Konon tempat ini merupakan petilasan kandang ayam yang di kenal dengan nama prabu Kian Santang. Warga percaya jika bila terdengar kokokan ayam tanda akan datangnya musibah kepada warga sekitar.

\begin{tabular}{lrr}
\multicolumn{1}{c}{ Ustadz } & Aar & Mubarak \\
menjelaskan bahwa antara & karang \\
paranje dan Prabu Kian & Santang \\
Wallahu'alam $\quad$ walaupun & dari \\
mediumisasi tidak ada hubungannya \\
semua itu. Cerita kokokan ayam itu \\
karena jelmaan jin yang berupa ayam.
\end{tabular}

c. Pada tanggal 11 Oktober 2013 dengan judul "Sumpah Bale Kambang"

Cerita ini berawal dari sebuah situs bernama "Bale Kambang yang berada di desa Ciledug Metan, kecamatan Cirebon. Dahulu Bale ini merupakan tempat untuk warga yang akan masuk Islam. Namun kini beralih fungsi menjadi tempat pengambilan sumpah. Sumpah Albiwar Jurnal Ilmu dan Teknik Dakwah Vol. 05 No. 09 Januari - Juni 2017 
mereka bukan atas nama Agama namun atas nama yang lain.

Ustadz Ujang Bustomi menyimpulkan marilah menjaga hati dan pikiran agar percaya hanya kepada Allah, dan selalu beristigfar atas semua kesalahan diri.Karena Allah Maha Pengampun.

d. Pada Tanggal 16 Oktober 2013 dengan judul "Pesugihan Krakalan"

Suatu tempat berupa sebuah pantai samas di bantul Jogjakarta.Masyarakat percaya tempat ini merupakan tempat berkumpulnya roh manusia yang tersesat dan meninggal tidak wajar.Tempat ini juga terkenal tempat jual beli makhluk ghaib di kalangan masyarakat.

\section{Ustadz Hakim Bawazier} mengatakan bahwa tempat yang berupa pengumpulan roh tersesat itu hanya kesalahan persepsi dari masyarakat.

e. Pada tanggal 18 Oktober 2013 dengan judul "Bekas Villa Kelasen"

Villa kosong yang menghadap ke arah pantai selatan di desa cimangke cilecep, kabupaten Garut.Villa tersebut tidak lagi digunakan oleh pemiliknya karena seringnya mendapatkan gangguan di tempat tersebut.

Ustadz Aar Mubarak menjelaskan bahwa gangguan di daerah tersebut memang merupakan dari bangsa jin.

f. Pada tanggal 23 Oktober 2013 dengan judul "Pancuran Emas Gumulung Tonggoh"

Kini mengisahkan tentang sebuah mata air keramat yang berada di daerah desa gumulung tonggoh kabupaten Cirebon.Mata air ini dipercaya dapat mengeluarkan emas bagi siapa saja yang menginginkan kekayaan dunia.

Ustadz Ujang Bustomi
menjelaskan secara logika apabila
manusia ingin kaya harus dengan kerja
keras dan meminta kepada Allah. Dan
apabila meminta kepada jin dengan
bertapa atau bersemedi maka orang
tersebut telah terjerumus di kesesatan
yang di buat oleh setan.

g. Pada tanggal 25 Oktober 2013 dengan judul "Rumah Pocong Banguntapan"

Sebuah rumah yang bernama benguntapan yang berada di dekat pos malang di kampong cilenan, bantul 
Jogjakarta. Dari informasi warga tempat tersebut aktivitas gaib memang sering terjadi di tempat tersebut.

Ustadz Hakim Bawazier mengatakan bahwa gangguan dari makhluk tersebut juga karena ulah manusia yang lewat tidak permisi.

h. Pada tanggal 30 Oktober 2013 dengan judul "Curug Rendeng"

Bertempat di desa curug rending, kabupaten subang. Tempat air terjun yang mempunyai nama curug rending konon tempat tersebut banyak menyimpan harta karun berasal dari para leluhur kampong tersebut.

Ustadz Ujang menyimpulkan bahwa harta yang ada tersebut bukanlah hak manusia.Sehingga apabila ingin kekayaan memintanya kepada Allah dengan bekerja keras dengan keyakinan terhadap Allah.

Pemahaman tentang isi dan tanggapan responden terhadap acara Dua Dunia Trans7

\footnotetext{
Isi pesan yang di pahami oleh responden berdasarkan masing-masing kategori
}

- Pandangan menurut Kategori latar belakang sekolah umum

Hasil dari kategori ini adalah hampir $100 \%$ dari mereka memahami isi materi yang di sampaikan dari acara ini.

- Pandangan menurut Kategori latar belakang agama

Kategori ini rata-rata memberikan pernyataan bahwa acara ini berisi pesan agama yang baik untuk memperbaiki keimanan seseorang.

- Pandangan menurut Kategori latar belakang orang awam

Kategori ini memberikan pernyataan yang beragam ada yang memperdulikan isi materi dari acara ini dan ada juga yang hanya menikmatinya sebagai hiburan.

Tanggapan penonton terhadap acara Dua Dunia Trans7 berdasarkan kategori:

- Pandangan menurut Kategori latar belakang sekolah umum

Ada yang antusias terhadap acara ini dan ada juga yang kurang.

- Pandangan menurut Kategori latar belakang sekolah agama 
Semua berpendapat kalau acara ini snagat bagus.

- Pandangan menurut Kategori latar belakang orang awam

Menurut mereka acara ini hanya hiburan saja.

\section{Analisis Data}

Tabel 4. DATA HASIL PEMAHAMAN RESPONDEN TERHADAP PESAN ACARA BERDASARKAN MASINGMASING KATEGORI

\begin{tabular}{|c|c|c|c|c|}
\hline $\begin{array}{c}\text { N } \\
\text { o }\end{array}$ & $\begin{array}{c}\text { Kategori } \\
\text { Responden }\end{array}$ & $\begin{array}{c}\text { Jumlah } \\
\text { Respond } \\
\text { en }\end{array}$ & $\begin{array}{c}\text { Paha } \\
\mathrm{m}\end{array}$ & $\begin{array}{c}\text { Kuran } \\
\mathrm{g} \\
\text { Paha } \\
\mathrm{m}\end{array}$ \\
\hline 1 & $\begin{array}{c}\text { Berpendidi } \\
\text { kan } \\
\text { Sekolah } \\
\text { Umum }\end{array}$ & 9 & $67 \%$ & $33 \%$ \\
\hline 2 & $\begin{array}{c}\text { Berpendidi } \\
\text { kan } \\
\text { Sekolah } \\
\text { Agama }\end{array}$ & 9 & $89 \%$ & $11 \%$ \\
\hline 3 & $\begin{array}{c}\text { Kurang } \\
\text { Berpendidi } \\
\text { kan }\end{array}$ & 9 & $78 \%$ & $22 \%$ \\
\hline 4 & Jumlah & 27 & $78 \%$ & $22 \%$ \\
\hline
\end{tabular}

Tabel 5. DATA HASIL TANGGAPAN

PARA RESPONDEN TERHADAP

ACARA DUA DUNIA TRANS7

BERDASARKAN MASING-MASING

KATEGORI

\begin{tabular}{|c|c|c|c|c|}
\hline $\begin{array}{c}\text { N } \\
\text { o }\end{array}$ & $\begin{array}{c}\text { Kategori } \\
\text { Responden }\end{array}$ & $\begin{array}{c}\text { Jumlah } \\
\text { Respond } \\
\text { en }\end{array}$ & $\begin{array}{c}\text { Paha } \\
\mathrm{m}\end{array}$ & $\begin{array}{c}\text { Kuran } \\
\mathrm{g} \\
\text { Paha } \\
\mathrm{m}\end{array}$ \\
\hline 1 & $\begin{array}{c}\text { Berpendidi } \\
\text { kan } \\
\text { Sekolah } \\
\text { Umum }\end{array}$ & 9 & $\begin{array}{c}100 \\
\%\end{array}$ & - \\
\hline 2 & $\begin{array}{c}\text { Berpendidi } \\
\text { kan } \\
\text { Sekolah } \\
\text { Agama }\end{array}$ & 9 & $78 \%$ & $22 \%$ \\
\hline 3 & $\begin{array}{c}\text { Kurang } \\
\text { Berpendidi } \\
\text { kan }\end{array}$ & 9 & $78 \%$ & $22 \%$ \\
\hline 4 & Jumlah & 27 & $85 \%$ & $15 \%$ \\
\hline
\end{tabular}

\section{Daftar Pustaka}

Al-Imam Jalaludin As-Suyuti,, Menguak Misteri Alam Ghaib, Kanza Publishing. 2011. Cet I. hal.23

H. Syaiful Rohim, Teori Komunikasi, Pt. Asdi MahaSatya, Jakarta 2009.

Jalaliddin Rahmat, Teori Komunikasi, Pt. Remaja Rosdakarya, Bandung 2011.

Light, G. and Cox, R, Learning and Teaching in Higher Education. London: Paul Chapman Publishing. 2001.

Muhammad Munir dan Wahyu Ilahi, Manajemen Dakwah, Rahmat semesta, Jakarta 2009.Cet. 2. 
Mulyono dan Bashuri, Studi Ilmu Tauhid atau Kalam, UIN Maliski, Maang 2010. Cet. 1

Nurudin, Pengantar Komunikasi Massa, PT. Raja Grapindo Persada, Jakarta 2007.

Onong Uchajana Effendy, ilmu, teori dan filsafat komunikasi, Pt. Citra Aditya Bakti, Bandung 2003

Subhani, Syaikh Ja'far, Tauhid dan Syirik, Mizan, Bandung. Hal.118

Stephen W. Litlejohn dan Karen A. Foss, Teori Komunikasi (Theories of Human Communication), Salemba Humanika, Jakarta Selatan 2009.

Sunarjo dan Djoenaesih S. Sunarjo, SU, Himpunan Istilah Komunikasi, Liberty, Yogyakarta 1995 cet. 1.

Werner J. Serverin, Teori Komunikasi, (ampang/hulukelang:Dewan bahasa dan pustaka, 1988) cet. I, h.186

Yasir Amri \& Alim Al-Adib, Syahirul, Sendiri Mengusir Gangguan Jin, PT Aqwam Media Profetika. Solo 2012.Hal. 12

http://www.trans7.co.id//programduadunia. 